\title{
Structure and function of the selectin ligand PSGL-1
}

R.D. Cummings

\section{Correspondence \\ R.D. Cummings \\ Department of Biochemistry and \\ Molecular Biology \\ The University of O klahoma \\ Health Sciences Center \\ 975 N.E. 10th St., BRC 417 \\ O klahoma City, OK 73104 \\ USA \\ Fax: + 1-405-271-3910 \\ E-mail: \\ richard-cummings@uokhsc.edu \\ Presented at the 5th Brazilian Symposium on Extracellular Matrix - SIM EC, Angra dos Reis, \\ RJ, Brasil, September 7-10, 1998. \\ Research supported by a grant from the $\mathrm{N}$ ational Institutes of $\mathrm{H}$ ealth (PO 1 HL 45510).}

Received March 2, 1999

Accepted March 9, 1999
Department of Biochemistry and Molecular Biology, The University of O klahoma Health Sciences Center, O klahoma City, OK, USA

\section{Abstract}

P-selectin glycoprotein ligand-1 (PSGL-1) is a dimeric mucin-like $120-\mathrm{kDa}$ glycoprotein on leukocyte surfaces that binds to P- and Lselectin and promotes cell adhesion in the inflammatory response. The extreme amino terminal extracellular domain of PSGL-1 is critical for these interactions, based on site-directed mutagenesis, blocking monoclonal antibodies, and biochemical analyses. The current hypothesis is that for high affinity interactions with P-selectin, PSGL-1 must contain O-glycans with a core- 2 branched motif containing the sialyl Lewis $\mathrm{x}$ antigen $(\mathrm{NeuAc} \alpha 2 \rightarrow 3 \mathrm{Gal} \beta 1 \rightarrow 4[\mathrm{Fuc} \alpha 1 \rightarrow 3] \mathrm{GlcNAc} \beta 1 \rightarrow \mathrm{R})$. In addition, high affinity interactions require the co-expression of tyrosine sulfate on tyrosine residues near the critical O-glycan structure. This review addresses the biochemical evidence for this hypothesis and the evidence that PSGL-1 is an important in vivo ligand for cell adhesion.

\section{Introduction}

The inflammatory response in animals is initiated by the tethering and rolling of circulating leukocytes on activated endothelium. These initial interactions involve glycoconjugate ligands on the leukocyte cell surface and carbohydrate-binding proteins, termed selectins, expressed on the surfaces of both endothelial cells and leukocytes. There are three known selectins, termed P-, E- and Lselectins, and all three are $\mathrm{Ca}^{2+}$-dependent binding proteins that contain a C-type carbohydrate recognition domain at their extreme $\mathrm{N}$-terminus. P-selectin is constitutively expressed in intracellular vesicles of platelets and endothelial cells and is rapidly mobilized to the surface membrane in thrombinor histamine-stimulated cells; E-selectin expression is transcriptionally up-regulated by inflammatory cytokines, and L-selectin is constitutively expressed on the surface membrane of all leukocytes.

Although initial studies suggested that all three selectins can recognize carbohydrates containing the sialyl Lewis $\mathrm{x}$ antigen $(\mathrm{NeuAc} \alpha 2 \rightarrow 3 \mathrm{Gal} \beta 1 \rightarrow 4[\mathrm{Fuc} \alpha 1 \rightarrow 3$ ] GlcNAcß1 $\rightarrow$ R) (sialyl Le ${ }^{\mathrm{x}}$ ), recent studies have now shown that each selectin demonstrates higher affinity binding to specific macromolecular ligands expressing sialylated and fucosylated glycans. To date the best characterized cell adhesion ligand for selectins is a dimeric mucin termed the P-selectin glycoprotein ligand-1 (PSGL-1). This mucin is expressed on the surface membranes of all leukocytes, but in regard to its binding to Pselectin, it is only functional on granulocytes and subclasses of lymphocytes. Interestingly, PSGL-1 may also serve as a ligand for both E- and L-selectin. The overall structure and biology of PSGL-1 have been discussed in 
several articles (1-5). This review will attempt to provide an overall historical framework for understanding the more important studies on this ligand and focus on exciting new developments in regard to the structure and function of PSGL-1 and its role as a selectin ligand in the inflammatory response and atherosclerosis.

\section{Historical studies on P-selectin ligands on neutrophils}

The binding of P-selectin to neutrophils is abolished upon sialidase treatment, which suggested originally that sialic acid may be a critical determinant required for P-selectin recognition (6). The possible importance of the sialyl Le ${ }^{\mathrm{x}}$ moiety to P-selectin recognition was derived from experiments showing that 1) P-selectin binds to a mutant Chinese hamster ovary $(\mathrm{CHO})$ cell line expressing the sialyl Le ${ }^{\mathrm{x}}$ moiety, but not to cells lacking the epitope (7);2) antibodies to the sialyl Le ${ }^{\mathrm{x}}$ epitope, but not the $\mathrm{Le}^{\mathrm{x}}$ epitope, can block binding of cells to P-selectin $(7,8)$, and 3$)$ glycans containing the sialyl Le $\mathrm{Le}^{\mathrm{x}}$ moiety can inhibit P-selectin-mediated adhesion (8). However, the binding of P-selectin to neutrophils displays much higher affinity interactions than to other non-myeloid cells (7), suggesting that myeloid cells possess one or more specific ligands for P-selectin. Using ${ }^{125}$ I-P-selectin blotting and affinity chromatography on immobilized human P-selectin, a glycoprotein ligand for P-selectin was identified and purified, starting with total membrane glycoproteins extracted from human neutrophils and the human promyelocytic cell line HL60 (9). The purified ligand, now known as the PSGL-1, behaves as a disulfide-bonded $\sim 250-\mathrm{kDa}$ protein in non-reducing SDS/PAGE and $\sim 120-\mathrm{kDa}$ in reducing SDS/PAGE.

\section{Primary structure of PSGL-1}

The cDNA encoding PSGL-1 was expression cloned in COS cells co-expressing an $\alpha 1,3 / 4$-fucosyltransferase (human FucTIII), which permits both sialyl Le ${ }^{\mathrm{x}}$ and sialyl Le $^{\mathrm{a}}$ synthesis in these cells (10). PSGL-1 is predicted to be a protein of 412 amino acids
Figure 1 - A, Scheme of the interactions between human Pselectin and the amino-terminal domain of human PSGL-1. The many N-glycans on PSGL-1 and $\mathrm{P}$-selectin are indicated, as are the O-glycans on PSGL-1. B, The major fucose-containing O-glycans of human HL60-derived PSGL-1. Glycan 1 is a trifucosylated, monosialylated, polylactosamine core-2 O-glycan and glycan 2 is a monofucosylated, disialylated core 2 O-glycan.

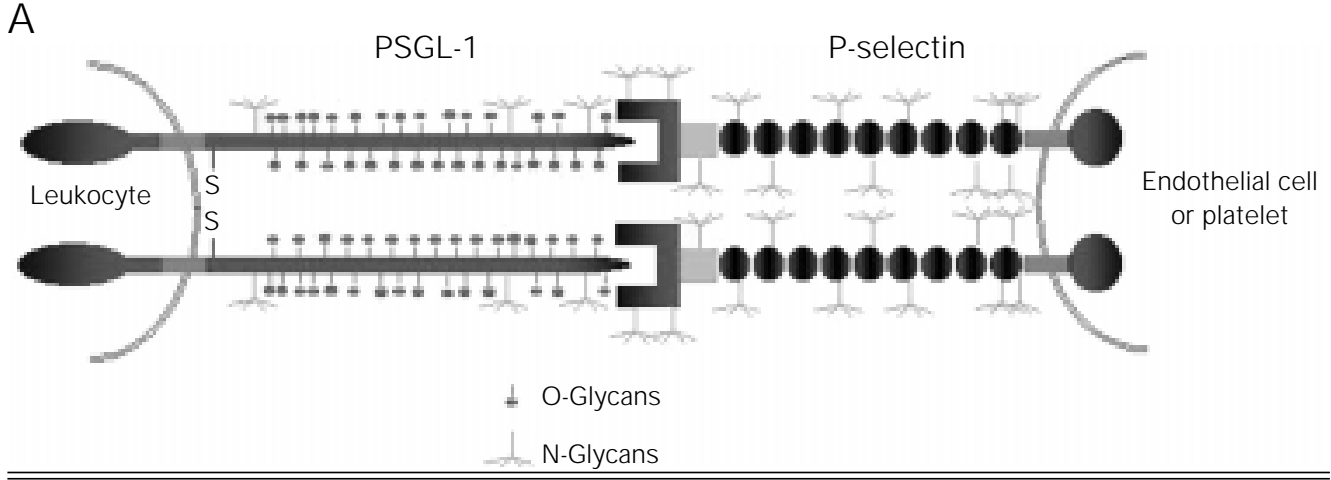

B

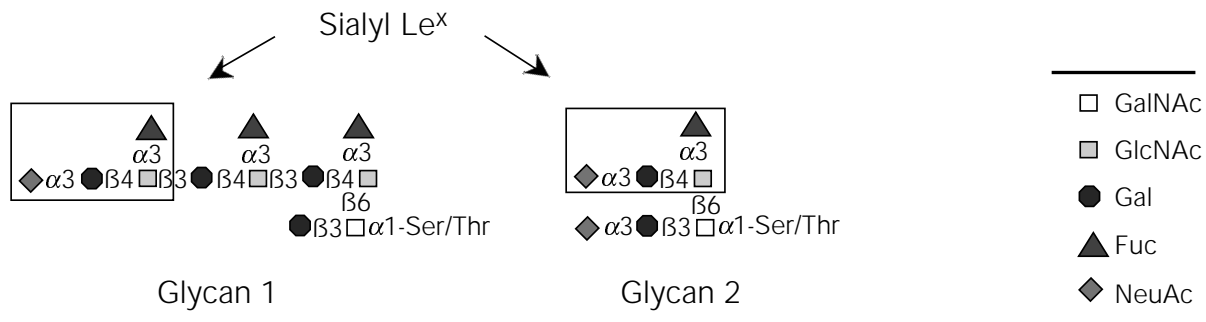


with an 18-amino acid signal sequence and a tetrapeptide consensus cleavage site for paired basic amino acid converting enzyme in leukocytes at residues 38-41 (-R-D-R-R-) (Figure 1A). Thus, the N-terminus of the mature protein begins at residue 42 . There are 16 decapeptide repeating units with the consensus sequence-A-T/M-E-A-Q-T-T-X$\mathrm{P} / \mathrm{L}-\mathrm{A} / \mathrm{T}$ - spanning residues $118-277$ in the long form of the protein and the short form is missing the residues 132-141 $(11,12)$. Within the extracellular domain is a single Cys residue at position 320 that precedes the predicted single transmembrane domain spanning residues 321-341 and the cytoplasmic domain of residues 342-412. The coding region for human PSGL-1 is contained entirely in exon 2 of the gene, which maps to chromosome 12q24. The cDNA for the murine PSGL-1 encodes a predicted 397-amino acid protein with recognizable homology to the human sequence (13). The murine protein contains a predicted signal sequence and propeptide identical in size to human PSGL-1; the mature murine PSGL-1 is also predicted to begin at residue 42 . However, the mouse homologue has only 10 decameric repeats with the consensus sequence-E-T-SQ/K-P-A-P-T/M-E-A- that are obviously different in sequence from the human PSGL-1. The highest homology between the human and murine PSGL-1 occurs in the transmembrane $(83 \%)$ and cytoplasmic domains (76\%).

Each subunit of human PSGL-1 contains $70 \mathrm{Ser}$ and $\mathrm{Thr}$ residues in the extracellular domain that are potential sites for O-glycosylation and 3 potential sites for $\mathrm{N}$-glycosylation. The murine PSGL-1 also contains numerous extracellular Ser and Thr residues and two potential sites for $\mathrm{N}$-glycosylation. The murine PSGL-1 also contains a single unpaired extracellular Cys at residue 307 that precedes the predicted transmembrane domain. Interestingly, the human PSGL-1 contains three predicted tyrosine sulfation sites at residues 46, 48 and 51 that fall in the consensus sequence in which Tyr residues are flanked by acidic residues. The murine PSGL-1 contains two predicted tyrosine sulfation sites at residues 54 and 56 .

\section{Structural features of PSG L-1 required for binding to $\mathrm{P}$-selectin}

\section{Glycosylation of native PSGL-1}

The large size and extensive glycosylation of PSGL-1 present a daunting challenge to understanding how it is specifically recognized by P-selectin. It was anticipated at first that PSGL-1 might be a high affinity and unique ligand for P-selectin by virtue of its mucin-like nature and the presumption that the ligand contained large amounts of the sialyl Le ${ }^{\mathrm{x}}$ antigen (14), thereby enhancing its avidity for P-selectin. However, as discussed below, this prediction was not correct.

Treatment of purified PSGL-1 with sialidase abolishes its binding to P-selectin, confirming the cell studies that indicated a role for sialic acid in P-selectin recognition $(9,14)$. Interestingly, treatment of neutrophil-derived PSGL-1 with peptide N-glycosidase $\mathrm{F}$, which removes most, if not all, the N-glycans of the molecule, does not affect its recognition by P-selectin, suggesting that O-glycans, but not $\mathrm{N}$-glycans, are important determinants (9). This conclusion is supported by the observation that treatment of either neutrophils or purified PSGL-1 with the O-sialoglycoprotease from Pasteurella hemolytica, an enzyme that degrades sialylated mucins, blocks all interactions with Pselectin (14). Furthermore, treatment of HL60 cells with benzyl-alpha-GalNAc, which inhibits extension of O-glycans, also reduces binding of cells to P-selectin (15). Other studies demonstrated that treatment of isolated PSGL-1 with endo-ß-galactosidase, a bacterial endoglycosidase capable of degrading type- 2 polylactosamine repeats [-3Galß1 $\rightarrow 4$ GlcNAcß1- $]_{\mathrm{n}}$, significantly reduces binding to P-selectin (16), thus indicating that the polylactosamine repeats, pre- 
sumably on O-glycans, may also be important for binding.

The O-glycans of native PSGL-1 purified from human HL60 cells were determined and the results were unexpected in many ways (17). Most of the O-glycans contained a simple core- 2 structure with one or two sialic acid residues and lacked fucose. Fucose was found in only two relatively minor O-glycans, termed glycan 1 and 2, as shown in Figure 1B. Both glycan 1 and 2 contain the sialyl Le ${ }^{\mathrm{x}}$ antigen; however, glycan 1, but not glycan 2, contains a polylactosamine backbone on the core-2 structure with multiple fucosyl residues. These results demonstrated that the O-glycans of PSGL-1 generally lacked fucose and that only a few O-glycans displayed the sialyl $\mathrm{Le}^{\mathrm{x}}$ antigen, presumed to be important in P-selectin binding. The fact that glycan 2 was predicted to occur in substoichiometric quantities led to the expectation that glycan 1 may be the more important $\mathrm{O}$-glycan for P-selectin recognition. This possibility is discussed below.

\section{Glycosylation of recombinant PSGL-1 required for binding to $P$-selectin}

To explore the functional importance of core-2 O-glycans and fucose residues in PSGL-1 activity, a recombinant form of PSGL-1 was expressed in CHO cells. These cells do not express the sialyl Le ${ }^{\mathrm{x}}$ antigen and lack $\alpha 1,3$-fucosyltransferases required for either $\mathrm{Le}^{\mathrm{x}}$ or sialyl $\mathrm{Le}^{\mathrm{x}}$ synthesis; in addition, they lack the $B 1,6-\mathrm{N}$-acetylglucosaminyltransferase (C2GnT) required for core- 2 O-glycan synthesis. PSGL-1 expressed in these wild type $\mathrm{CHO}$ cells was not able to bind P-selectin (18). However, PSGL-1 synthesized in $\mathrm{CHO}$ cells co-transfected with cDNA encoding human $\alpha 1,3$-fucosyltransferase III (Fuc-TIII) and the human C2GnT was a high affinity ligand for P-selectin $(18,19)$. Such results suggested that expression of both the sialyl $\mathrm{Le}^{\mathrm{x}}$ antigen and $\mathrm{C} 2 \mathrm{GnT}$ is required for PSGL-1 binding to P-selectin.
Tyrosine sulfation and the role of the PSGL-1 $\mathrm{N}$-terminus

Although glycosylation of PSGL-1 is clearly important for its binding to P-selectin, other biochemical studies of the molecule have provided several clues suggesting that sulfation was also important. The first of these clues was that PSGL-1 contained tyrosine sulfate and that removal of tyrosine sulfate by bacterial aryl sulfatases abrogated binding of the molecule to P-selectin (20). Consistent with this finding, recombinant forms of PSGL-1 in which the three tyrosine residues had been mutagenized to phenylalanine also failed to bind P-selectin $(21,22)$. In addition, treatment of cells with sodium chlorate, an inhibitor of the ATP sulfurylase that is required for synthesis of the sulfate donor phosphoadenosine phosphosulfate (PAPS), also blocked synthesis of a functional PSGL-1 molecule $(21,22)$.

These results suggested that the critical binding domain may reside in the extreme amino terminus of PSGL-1. Four different lines of experimentation are consistent with this possibility. 1) Moore et al. (12) developed a blocking mAb (PL1) that mapped to a peptide epitope overlapping the tyrosine sulfate consensus sites, whereas non-blocking monoclonal antibodies (e.g. PL2) mapped to epitopes outside this region (23). Other studies showed that such blocking mAb prevent neutrophil, monocyte, eosinophil and lymphocyte adhesion and rolling on to P- and Lselectin $(12,24,25) .2)$ Pouyani and Seed (22) constructed a chimeric mucin in which the first 100 amino acids from the N-terminus of PSGL-1 were grafted onto the Ntermini of CD43 and CD34, two mucins that are normally expressed on leukocytes. The chimeric proteins, but not the native forms of CD43 or CD34, expressed by COS cells co-transfected with Fuc-TVII, were bound by P-selectin. 3) A chimeric form of PSGL1 , in which the 19 amino acid segment from the extreme N-terminus of mature PSGL-1 
was fused to the heavy chain $\mathrm{C}_{\mathrm{H}} 2-\mathrm{C}_{\mathrm{H}} 3$ region of $\operatorname{IgG} 1$, and the recombinant glycoprotein expressed in COS cells co-transfected with human Fuc-TIII, was bound by Pselectin (21). 4) Treatment of neutrophils with the cobra venom metalloproteinase mocarhagin removed the extreme N-terminal 10 amino acid residues from PSGL-1 and abrogated its binding to P-selectin (26). All of these experiments point to a model in which the combination of tyrosine sulfate residues and oligosaccharides on the protein are required for high affinity binding to $\mathrm{P}$ selectin.

An additional approach to explore the fine structure of the PSGL-1 N-terminal domain required for $\mathrm{P}$-selectin recognition is to selectively mutate amino acids in that domain and test the binding of recombinant PSGL-1 to P-selectin. Such site-directed mutagenesis to replace all three $\mathrm{N}$-terminal Tyr residues with Phe abolishes binding of the recombinant PSGL-1 to P-selectin, but not E-selectin $(18,21,22)$. A more detailed number of mutations reveal that any one of the three Tyr residues can support binding of the recombinant PSGL-1 to P-selectin, indicating that only one of the three potential tyrosine sulfate residues is necessary for binding to P-selectin (27). Furthermore, mutation of the Thr residue at position 57 to Ala in the extreme $\mathrm{N}$-terminus human PSGL-1 blocks binding of the recombinant molecule to P-selectin $(21,22,27)$. Taken together, the studies on the native and recombinant PSGL1 support the types of models shown in Figure 2, where one or more tyrosine sulfate residues acting in conjunction with nearby Thr-attached O-glycans and with a sialyl Le ${ }^{\mathrm{x}}$ antigen on the core-2 motif are recognized by P-selectin. However, it must be stressed that this model is a mere prediction. Despite the elegant experiments described above, there is still no chemical proof that such Olinked glycans, as depicted in Figure 2, occur at Thr-57 in PSGL-1; nor is there any direct proof that there is coordinate binding of such an O-glycan and one or more tyrosine sulfates.

\section{Affinity of PSGL-1 for P-selectin}

Previous studies have established that Pselectin binds to free glycans containing sialyl Le $^{\mathrm{x}}$ with relatively low affinity in the millimolar range $(0.1$ to $1.0 \mathrm{mM})$. However, recent studies using a BIAcore apparatus and surface plasmon resonance measurements demonstrated that neutrophil-derived PSGL1 is a high affinity ligand for P-selectin and exhibits a $K_{d}$ in the range of $0.3 \mu \mathrm{M}(28)$. The binding is characterized by a high off-rate counterbalanced by an even higher on-rate. This high affinity between PSGL-1 and Pselectin contrasts with that observed for Lselectin binding to GlyCAM-1, where the $\mathrm{K}_{\mathrm{d}}$ is in the range of $0.1 \mathrm{mM}$, which was also determined by surface plasmon resonance measurements (29). The binding of recombinant forms of PSGL-1 to P-selectin has also recently been measured and found to have a very high affinity. The $\mathrm{K}_{\mathrm{d}}$ of soluble P-selectin with a soluble recombinant form of PSGL-1, which was prepared using human Fuc-TIII, was determined by measuring changes in intrinsic fluorescence upon ligand

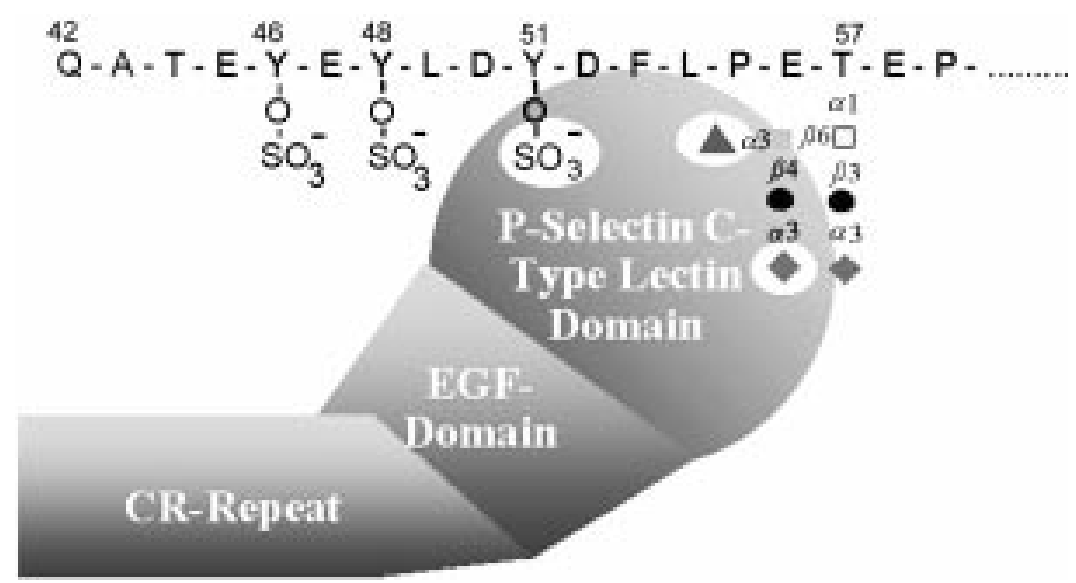

Figure 2 - Predicted interaction between the extreme amino terminal domain of human PSGL-1 and human P-selectin. The putative sites of interactions with tyrosine sulfate residues and the sialic acid and fucose residues of the core 2 O-glycan (glycan 2 of Figure 1) are indicated. 
binding and found to be in the range of $3 \mathrm{nM}$ (30). Interestingly, when the recombinant PSGL-1 was prepared with human Fuc-TVII, the $K_{d}$ was large and in the range of 80 $\mathrm{nM}$ (30). Although many questions remain about the relative glycosylation of native versus recombinant PSGL-1 in such studies as those cited above, these results demonstrate that PSGL-1 is a high affinity ligand for P-selectin.

\section{Dimerization of PSGL-1}

To explore the role of dimerization of PSGL-1 on its ability to mediate cell adhesion and recognition by P-selectin, two laboratories prepared a recombinant form of the molecule in which the single extracellular Cys residue in PSGL-1 was changed to Ala $(31,32)$. Essentially both groups found that the mutated protein behaved as a monomeric protein under reducing and non-reducing conditions and that the mutated protein displayed no affinity for P-selectin. These results were taken to indicate that PSGL-1 dimerization is essential for its high affinity binding to P-selectin. However, more recent studies in our laboratory have now provided data which question the results of these studies. Similar substitution of the single extracellular Cys with either Ala or Ser appear to have no discernible effect on binding of cells expressing the mutated protein to P-selectin (Epperson TK, Ramachandran V, Patel KD, McEver RP and Cummings RD, unpublished data). Furthermore, in the latter study it was found that the mutated PSGL-1 behaved as a non-covalent dimeric protein that was readily cross-linked in the membrane form to a dimer. In addition, a small tryptic fragment of $\sim 9$ $\mathrm{kDa}$, prepared from the recombinant molecule and containing the extreme $\mathrm{N}$-terminal domain of the molecule, bound quantitatively to a column of immobilized P-selectin. These results suggest that covalent dimerization of PSGL-1 is not required for its functional association with P-selectin. However, because PSGL-1 can non-covalently dimerize in the membrane, more studies will be needed in the future to define the significance of dimerization on activity of the membrane-bound ligand for binding to selectins.

\section{Signaling functions of PSG L-1}

PSGL-1 may have much more than a passive role in mediating adhesion. It may also be an important signaling molecule to neutrophils. Upon activation of polymorphonuclear leukocytes there is a redistribution of PSGL-1 resulting in a lowering of affinity of activated cells for P-selectin (33). Incubation of neutrophils with either Pselectin or the monoclonal antibody PL1 to PSGL-1 stimulates tyrosine phosphorylation of several proteins and production of IL-8 (34). This pathway of activation appears to activate GTPase Ras and the MAP kinase cascade (34). Other studies indicate that ligation of neutrophils with anti-PSGL-1 monoclonal antibodies and/or P-selectin triggers $\beta_{2}$-integrin-dependent and genestein-sensitive cell aggregation and tyrosine phosphorylation (35). The precise molecular mechanism(s) by which PSGL-1 is triggering these biochemical changes are presently unclear. It is intriguing to consider that dimerization of the ligand may be more important to cytoskeletal interactions and cell signaling than to cell adhesion.

\section{Studies of P-selectin ligands in vivo}

In vivo approaches to understanding structure/function relationships of glycans in selectin ligand function have recently provided exciting new insights and have partly confirmed predictions about the importance of sialyl Le ${ }^{\mathrm{x}}$ and core-2 O-glycans for PSGL1 recognition by P-selectin. Neutrophils from null mice lacking the myeloid enzyme FucTVII bind poorly to P-, E- or L-selectin, and neutrophil efflux in experimentally induced inflammation is dramatically reduced (36). 
Similarly, the binding of $\mathrm{T}$ lymphoblasts from Fuc-TVII-null mice to P-selectin is reduced (37). Interestingly, it has recently been shown that both human Fuc-TIV and FucTVII are required to synthesize polyfucosylated polylactosamine in vitro, such as found on glycan-1 (Figure 1B) (38). Whether these enzymes act cooperatively in vivo is not known. More recent studies show that the core-2 O-glycans are also critically important for neutrophil interactions with all three selectins. Neutrophils from null mice lacking the $\mathrm{C} 2 \mathrm{GnT}$ bind poorly to P-selectin in fluid-phase studies, although the cells still demonstrate adhesion under shear stress to $\mathrm{P}$-selectin that is much greater than that seen for Fuc-TVII-null mice (39). Although the structures of $\mathrm{O}-$ and $\mathrm{N}$-glycans on murine leukocytes are not known, these studies strongly support the observations on human PSGL-1 that core-2 O-glycans containing the sialyl $\mathrm{Le}^{\mathrm{x}}$ antigen are important in $\mathrm{P}$ selectin recognition.

The specific in vivo functions of PSGL-1 has been explored using both blocking antibodies to the protein and recombinant forms. A blocking mAb to PSGL-1 (PL1) and its $\mathrm{F}(\mathrm{ab})$ fragments dramatically reduced rolling of human polymorphonuclear neutrophils and HL60 cells in venules of acutely exteriorized rat mesentery, indicating that PSGL-1 is important in vivo for rolling of myeloid cells in mesenteric venules at physiologic shear stress (40). Another approach to study PSGL-1 function in vivo during inflammation is to explore its role in ischemia/ reperfusion injury models, in which blood flow is blocked, thereby stimulating Pselectin expression by endothelial cells. In a rat model of ischemia/reperfusion injury, using hepatic in vivo warm ischemia and ex vivo cold ischemia in a liver transplant experiment (41), animals were treated with $100 \mu \mathrm{g}$ of recombinant PSGL-1 injected through the portal vein at the time of total hepatic inflow occlusion or into the isolated organ. Treatment with the soluble recombi- nant PSGL-1 significantly enhanced rat survival and liver function and recovery. PSGL1 may also be important for lymphocyte recruitment to sites of inflammation in vivo, since intravenous administration of antibodies to the extreme $\mathrm{N}$-terminus of mouse PSGL-1 block migration of Th1 T-lymphocytes into skin undergoing cutaneous delayed-type hypersensitivity reactions (42) and block rolling of leukocytes in venules of acutely exposed mouse cremaster muscle (43). Although these studies strongly support a role for PSGL-1 in leukocyte function in vivo, many more studies are needed to more precisely define the involvement of PSGL-1, as opposed to or in concert with other selectin ligands, in the overall response to inflammation.

Accumulation of circulating leukocytes, especially monocytes, is a recognized early event in development of atherosclerosis. Some exciting new studies are suggesting that P- and E-selectin may contribute to development of early and advanced stages of atherosclerotic lesions. Mice deficient for both P- and E-selectin (P/E-/-), combined with a deficiency in the LDL receptor (LDLR -/-) as a model system, developed fatty lesions that were smaller than those in mice with normal P- and E-selectin (LDLR-/-, P/ $\mathrm{E}+/+$ ) and the development of lesions was delayed (44). However, whether PSGL-1 is involved in the development of these lesions is not yet known.

\section{Role of PSG L-1 as a ligand for L- and E-selectin}

All three selectins can bind weakly to simple glycans containing the sialyl $\mathrm{Le}^{\mathrm{x}}$ determinant; however, as demonstrated for Pselectin and PSGL-1, such binding is relatively weak and macromolecular ligands bind with higher affinity. Although several glycoproteins are recognized by L- and E-selectin, whether these ligands serve physiologically to support selectin-mediated cell adhesion is 
still not clear (3). Interestingly, gathering evidence is indicating that PSGL-1 may be a physiological ligand for L-selectin (45-47) and may participate in some E-selectin-dependent adhesion. For example, neutrophil tethering to P- and E-selectin is inhibitable by blocking monoclonal antibody PL1 to PSGL-1, although the inhibition is much more efficient toward P-selectin and Eselectin (45). The results suggest that PSGL1 is a high affinity ligand for P-selectin and perhaps a low affinity ligand for E-selectin. Furthermore, this interaction of PSGL-1 with E-selectin is not dependent on tyrosine sulfation of PSGL-1 (48). More interestingly, leukocyte tethering to L-selectin under shear stress is highly inhibitable by PL1, indicating a potential role for PSGL-1/Lselectin interactions in neutrophil-neutrophil interactions as a way of amplifying the initial leukocyte accumulation that is dependent on P-selectin (49). However, there may be other mucin-like receptors for L-selectin on leukocytes, as recently suggested by studies of Ramos et al. (50). All of these results are beginning to suggest that PSGL-1 is probably a physiological ligand for P- and Lselectin and may contribute to some Eselectin-dependent interactions.

\section{Future directions}

The past few years have seen an explosive growth in our knowledge of the structures and functions of selectins, but our understanding of selectin ligands involved in cell adhesion is still limited. PSGL-1 represents the best characterized adhesion ligand to date, but many questions still remain. Do both P- and L-selectin dually recognize tyrosine sulfate and sialyl $\mathrm{Le}^{\mathrm{x}}$ residues? Are there specific binding sites for both determinants on these selectins? If only the extreme $\mathrm{N}$-terminal domain of PSGL-1 is responsible for its interactions with P-selectin (and perhaps L-selectin), what is the function of the proximal region of the mucin? What is the role of dimerization of PSGL-1? How does ligation of PSGL-1, an extended mucin, function as a signaling molecule in leukocytes? What is the function of PSGL-1 in most lymphocytes, where it is expressed in a glycoform that appears incapable of binding to P-selectin? These and many more questions are being eagerly explored in many laboratories around the world, and it is anticipated that the coming years will yield exciting new insights into the function of PSGL-1 and related mucin selectin ligands.

\section{References}

1. Yang J, Furie BC \& Furie B (1999). The biology of P-selectin glycoprotein ligand1 : its role as a selectin counterreceptor in leukocyte-endothelial and leukocyte-platelet interaction. Thrombosis and Haemostasis, 81: 1-7.

2. Moore KL (1998). Structure and function of P-selectin glycoprotein ligand-1. Leukemia and Lymphoma, 29: 1-15.

3. McEver RP (1997). Selectin-carbohydrate interactions during inflammation and metastasis. Glycoconjugate J ournal, 14: 585591.

4. McEver RP \& Cummings RD (1997). Role of PSGL-1 binding to selectins in leukocyte recruitment. J ournal of Clinical Investigation, 100: 485-491.

5. Lowe J B (1997). Selectin ligands, leuko- cyte trafficking, and fucosyltransferase genes. Kidney International, 51: 14181426.

6. Moore KL, Varki A \& McEver RP (1991). GM P-140 binds to a glycoprotein receptor on human neutrophils: evidence for a lectin-like interaction. J ournal of Cell Biology, 112: 491-499.

7. Zhou Q, Moore KL, Smith DF, Varki $A$, McEver RP \& Cummings RD (1991). The selectin GMP-140 binds to sialylated, fucosylated lactosaminoglycans on both myeloid and nonmyeloid cells. J ournal of Cell Biology, 115: 557-564.

8. Polley MJ, Phillips ML, Wayner E, Nudelman E, Singhal AK, Hakomori S \& Paulson J C (1991). CD62 and endothelial cell-leukocyte adhesion molecule 1
(ELAM-1) recognize the same carbohydrate ligand, sialyl-Lewis $x$. Proceedings of the National Academy of Sciences, USA, 88: 6224-6228.

9. Moore KL, Stults NL, Diaz S, Smith DF, Cummings RD, Varki $A$ \& McEver RP (1992). Identification of a specific glycoprotein ligand for P-selectin (CD62) on myeloid cells. J ournal of Cell Biology, 118: 445-456.

10. Sako D, Chang XJ, Barone KM, Vachino G, White HM, Shaw G, Veldman GM, Bean KM, Ahern TJ, Furie B, Cumming DA \& Larsen GR (1993). Expression cloning of a functional glycoprotein ligand for P-selectin. Cell, 75: 1179-1186.

11. Veldman GM, Bean KM, Cumming DA, Eddy RL, Sait SN \& Shows TB (1995). 
Genomic organization and chromosomal localization of the gene encoding human P-selectin glycoprotein ligand. J ournal of Biological Chemistry, 270: 16470-16475.

12. Moore KL, Patel KD, Bruehl RE, Li F, J ohnson DA, Lichenstein HS, Cummings RD, Bainton DF \& McEver RP (1995). Pselectin glycoprotein ligand-1 mediates rolling of human neutrophils on P-selectin. J ournal of Cell Biology, 128: 661-671.

13. Yang J , Galipeau J , Kozak CA, Furie BC \& Furie B (1996). Mouse P-selectin glycoprotein ligand-1: molecular cloning, chromosomal localization, and expression of a functional P-selectin receptor. Blood, 87: 4176-4186.

14. Norgard KE, Moore KL, Diaz S, Stults NL, Ushiyama S, McEver RP, Cummings RD \& Varki A (1993). Characterization of a specific ligand for $\mathrm{P}$-selection on myeloid cells. A minor glycoprotein with sialylated O-linked oligosaccharides. J ournal of Biological Chemistry, 268: 12764-12774.

15. Kojima N, Handa K, Newman W \& Hakomori S (1992). Inhibition of selectindependent tumor cell adhesion to endothelial cells and platelets by blocking $\mathrm{O}$ glycosylation of these cells. Biochemical and Biophysical Research Communications, 182: 1288-1295.

16. Moore KL, Eaton SF, Lyons DE, Lichenstein HS, Cummings RD \& McEver RP (1994). The P-selectin glycoprotein ligand from human neutrophils displays sialylated, fucosylated, O-linked poly-N-acetyllactosamine. J ournal of Biological Chemistry, 269: 23318-23327.

17. Wilkins PP, McEver RP \& Cummings RD (1996). Structures of the O-glycans on Pselectin glycoprotein ligand-1 from HL-60 cells. J oumal of Biological Chemistry, 271 : 18732-18742.

18. Li F, Wilkins PP, Crawley S, Weinstein J , Cummings RD \& M CEver RP (1996). Posttranslational modifications of recombinant P-selectin glycoprotein ligand-1 required for binding to $\mathrm{P}$ - and E-selectin. J ournal of Biological Chemistry, 271: 3255-3264.

19. Kumar R, Camphausen RT, Sullivan FX \& Cumming DA (1996). Core2 beta-1,6-Nacetylglucosaminyltransferase enzyme activity is critical for P-selectin glycoprotein ligand-1 binding to P-selectin. Blood, 88: 3872-3879.

20. Wilkins PP, Moore KL, Li F, McEver RP \& Cummings RD (1995). Tyrosine sulfation of P-selectin glycoprotein ligand- 1 is required for high affinity binding to Pselectin. J ournal of Biological Chemistry, 270: 22677-22680.

21. Sako D, Comess KM, Barone KM,
Camphausen RT, Cummings DA \& Shaw GD (1995). A sulfated peptide segment at the amino terminus of PSGL-1 is critical for P-selectin binding. Cell, 83: 323-331.

22. Pouyani T \& Seed B (1995). PSGL-1 recognition of P-selectin is controlled by a tyrosine sulfation consensus at the PSGL1 amino terminus. Cell, 83: 333-343.

23. Li F, Erickson HP, J ames J A, Moore KL, Cummings RD \& McEver RP (1996). Visualization of P-selectin glycoprotein ligand1 as a highly extended molecule and mapping of protein epitopes for monoclonal antibodies. J ournal of Biological Chemistry, 271: 6342-6348.

24. Patel KD \& McEver RP (1997). Comparison of tethering and rolling of eosinophils and neutrophils through selectins and Pselectin glycoprotein ligand-1. J ournal of Immunology, 159: 4555-4565.

25. Lim YC, Snapp K, Kansas GS, Camphausen R, Ding $\mathrm{H} \&$ Luscinskas FW (1998). Important contributions of Pselectin glycoprotein ligand-1-mediated secondary capture to human monocyte adhesion to P-selectin, E-selectin, and TNF-alpha-activated endothelium under flow in vitro. Immunology, 161: 25012508.

26. De Luca M, Dunlop LC, Andrews RK, Flannery J r J V, Ettling R, Cumming DA, Veldman GM \& Bemdt MC (1995). A novel cobra venom metalloproteinase, mocarhagin, cleaves a 10-amino acid peptide from the mature $\mathrm{N}$ terminus of $\mathrm{P}$-selectin glycoprotein ligand receptor, PSGL-1, and abolishes P-selectin binding. J ournal of Biological Chemistry, 270: 26734-26737.

27. Liu W, Ramachandran V, Kang J, Kishimoto TK, Cummings RD \& McEver RP (1998). Identification of N-terminal residues on P-selectin glycoprotein ligand-1 required for binding to P-selectin. J ournal of Biological Chemistry, 273: 7078-7087.

28. Mehta P, Cummings RD \& McEver RP (1998). Affinity and kinetic analysis of Pselectin binding to $\mathrm{P}$-selectin glycoprotein ligand-1. J oumal of Biological Chemistry, 273: 32506-32513.

29. Nicholson MW, Barclay AN, Singer MS, Rosen SD \& van der Merwe PA (1998). Affinity and kinetic analysis of L-selectin (CD62L) binding to glycosylation-dependent cell-adhesion molecule-1. J ournal of Biological Chemistry, 273: 763-770.

30. Croce K, Freedman SJ , Furie BC \& Furie B (1998). Interaction between soluble Pselectin and soluble P-selectin glycoprotein ligand 1: equilibrium binding analysis. Biochemistry, 37: 16472-16480.

31. Fujimoto TT, Noda M, Takafuta T,
Shimomura T, Fujimura K \& Kuramoto A (1996). Expression and functional characterization of the P-selectin glycoprotein ligand-1 in various cells. International J ournal of Hematology, 64: 231-239.

32. Snapp KR, Craig R, Herron M, Nelson RD, Stoolman LM \& Kansas GS (1998). Dimerization of P-selectin glycoprotein ligand-1 (PSGL-1) required for optimal recognition of P-selectin. J ournal of Cell Biology, 142: 263-270.

33. Lorant DE, McEver RP, Mclntyre TM, Moore KL, Prescott SM \& Zimmerman GA (1995). Activation of polymorphonuclear leukocytes reduces their adhesion to P-selectin and causes redistribution of ligands for P-selectin on their surfaces. J ournal of Clinical Investigation, 96: 171182.

34. Hidari KI, Weyrich AS, Zimmerman GA \& McEver RP (1997). Engagement of Pselectin glycoprotein ligand-1 enhances tyrosine phosphorylation and activates mitogen-activated protein kinases in human neutrophils. J ournal of Biological Chemistry, 272: 28750-28756.

35. Evangelista $V$, Manarini $S$, Sideri $R$, Rotondo S, Martelli N, Piccoli A, Totani L, Piccardoni P, Vestweber D, de Gaetano G \& Cerletti C (1999). Platelet/polymorphonuclear leukocyte interaction: P-selectin triggers protein-tyrosine phosphorylationdependent $\mathrm{CD} 11 \mathrm{~b} / \mathrm{CD} 18$ adhesion: role of PSGL-1 as a signaling molecule. Blood, 93: 876-885.

36. Maly P, Thall A, Petryniak B, Rogers CE, Smith PL, Marks RM, Kelly RJ, Gersten KM, Cheng G, Saunders TL, Camper SA, Camphausen RT, Sullivan FX, Isogai $Y$, Hindsgaul O, von Andrian UH \& Lowe J B (1996). The $\alpha(1,3)$ fucosyltransferase FucTVII controls leukocyte trafficking through an essential role in L-, E-, and P-selectin ligand biosynthesis. Cell, 86: 643-653.

37. Knibbs RN, Craig RA, Maly P, Smith PL, Wolber FM, Faulkner NE, Lowe J B \& Stoolman LM (1998). $\alpha(1,3)$-fucosyltransferase VII-dependent synthesis of $\mathrm{P}$ - and E-selectin ligands on cultured T lymphoblasts. J ournal of Immunology, 161: 63056315.

38. Niemela R, Natunen J, Majuri ML, Maaheimo H, Helin J , Lowe J B, Renkonen $\mathrm{O} \&$ Renkonen R (1998). Complementary acceptor and site specificities of Fuc-TIV and Fuc-TVII allow effective biosynthesis of sialyl-TriLe ${ }^{x}$ and related polylactosamines present on glycoprotein counterreceptors of selectins. J ournal of Biological Chemistry, 273: 4021-4026.

39. Ellies LG, Tsuboi S, Petryniak B, Lowe J B, 
Fukuda M \& Marth JD (1998). Core 2 oligosaccharide biosynthesis distinguishes between selectin ligands essential for leukocyte homing and inflammation. Immunity, 9: 881-890.

40. Norman KE, Moore KL, McEver RP \& Ley $\mathrm{K}$ (1995). Leukocyte rolling in vivo is mediated by $\mathrm{P}$-selectin glycoprotein ligand-1. Blood, 86: 4417-4421.

41. Dulkanchainun TS, Goss J A, Imagawa DK, Shaw GD, Anselmo DM, Kaldas F, Wang T, Zhao D, Busuttil AA, Kato $H$, Murray NG, Kupiec-Weglinski J W \& Busuttil RW (1998). Reduction of hepatic ischemia/reperfusion injury by a soluble P-selectin glycoprotein ligand-1. Annals of Surgery, 227: 832-840.

42. Borges $E$, Tietz $W$, Steegmaier $M$, Moll T, Hallmann R, Hamann A \& Vestweber D (1997). P-selectin glycoprotein ligand-1 (PSGL-1) on T helper 1 but not on Thelper 2 cells binds to P-selectin and supports migration into inflamed skin. J ournal of Experimental Medicine, 185: 573-578.

43. Borges E, Eytner R, Moll T, Steegmaier
M, Campbell MA, Ley K, Mossmann H \& Vestweber D (1997). The P-selectin glycoprotein ligand-1 is important for recruitment of neutrophils into inflamed mouse peritoneum. Blood, 90: 1934-1942.

44. Dong ZM, Chapman SM, Brown AA, Frenette PS, Hynes RO \& Wagner DD (1998). The combined role of P- and Eselectins in atherosclerosis. Journal of Clinical Investigation, 102: 145-152.

45. Patel KD, Moore KL, Nollert MU \& McEver RP (1995). Neutrophils use both shared and distinct mechanisms to adhere to selectins under static and flow conditions. J ournal of Clinical Investigation, 96: 18871896.

46. Spertini O, Cordey AS, Monai N, Giuffre L \& Schapira M (1996). P-selectin glycoprotein ligand 1 is a ligand for L-selectin on neutrophils, monocytes, and CD34+ hematopoietic progenitor cells. J ournal of Cell Biology, 135: 523-531.

47. Guyer DA, Moore KL, Lynam EB, Schammel CM, Rogelj S, McEver RP \& Sklar LA (1996). P-selectin glycoprotein ligand-1 (PSGL-1) is a ligand for L-selectin in neutrophil aggregation. Blood, 88: 2415-2421.

48. Goetz DJ , Greif DM, Ding H, Camphausen RT, Howes S, Comess KM, Snapp KR, Kansas GS \& Luscinskas FW (1997). Isolated P-selectin glycoprotein ligand-1 dynamic adhesion to $P$ - and E-selectin. J ournal of Cell Biology, 137: 509-519.

49. Walcheck B, Moore KL, McEver RP \& Kishimoto TK (1996). Neutrophil-neutrophil interactions under hydrodynamic shear stress involve L-selectin and PSGL1. A mechanism that amplifies initial leukocyte accumulation of P-selectin in vitro. J ournal of Clinical Investigation, 98: 10811087.

50. Ramos CL, Smith MJ , Snapp KR, Kansas GS, Stickney GW, Ley K \& Lawrence MB (1998). Functional characterization of Lselectin ligands on human neutrophils and leukemia cell lines: evidence for mucin like ligand activity distinct from P-selectin glycoprotein ligand-1. Blood, 91: 10671075. 